\title{
Exercise Machines in Speed and Coordination Development among Students Playing Basketball
}

\author{
Oleksii Tymoshenko', Valery Arefiev", Zhanna Domina', Tetiana Malechko ${ }^{1}$, Tetiana Bondar ${ }^{1}$, \\ Mykola Tymchyk ${ }^{1}$, Olena Pliushchakova ${ }^{1}$, Viktor Riabchenko ${ }^{2}$, Grygoriy Griban ${ }^{3, *}$, \\ Kostiantyn Prontenko ${ }^{4}$
}

\footnotetext{
${ }^{1}$ Department of the Theory and Methodology of Physical Education, National Pedagogical Dragomanov University, Kyiv, 02000, Ukraine

${ }^{2}$ Department of Physical Education, Academy of the State Penitentiary Service, Chernihiv, 14000, Ukraine

${ }^{3}$ Department of Physical Education and Sport Improvement, Zhytomyr Ivan Franko State University, Zhytomyr, 10002, Ukraine ${ }^{4}$ Department of Physical Education, Special Physical Training and Sport, S. P. Koroliov Zhytomyr Military Institute, Zhytomyr, 10008, Ukraine
}

Received January 21, 2021; Revised March 4, 2021; Accepted March 23, 2021

\section{Cite This Paper in the following Citation Styles}

(a): [1] Oleksii Tymoshenko, Valery Arefiev, Zhanna Domina, Tetiana Malechko, Tetiana Bondar, Mykola Tymchyk, Olena Pliushchakova, Viktor Riabchenko, Grygoriy Griban, Kostiantyn Prontenko , "Exercise Machines in Speed and Coordination Development among Students Playing Basketball," International Journal of Human Movement and Sports Sciences, Vol. 9, No. 2, pp. 347 - 355, 2021. DOI: 10.13189/saj.2021.090224.

(b): Oleksii Tymoshenko, Valery Arefiev, Zhanna Domina, Tetiana Malechko, Tetiana Bondar, Mykola Tymchyk, Olena Pliushchakova, Viktor Riabchenko, Grygoriy Griban, Kostiantyn Prontenko (2021). Exercise Machines in Speed and Coordination Development among Students Playing Basketball. International Journal of Human Movement and Sports Sciences, 9(2), 347 - 355. DOI: 10.13189/saj.2021.090224.

Copyright@2021 by authors, all rights reserved. Authors agree that this article remains permanently open access under the terms of the Creative Commons Attribution License 4.0 International License

\begin{abstract}
The article presents the original methodology for using exercise machines to develop speed and coordination of students playing basketball in order to improve traditional approaches to physical education of basketball players. The introduction of exercise machines in the training process increases the developmental effect of exercises due to the possibility of a targeted impact on physical qualities together with training, accurate dosing of physical parameters, and an increase in motor activity in classes. The study involved 169 students who play basketball between the ages of 17 and 23. Experimental (EG) and control (CG) groups, which included 127 and 42 students respectively, were formed. The EG students played basketball in classes using exercise machines according to the methodology developed. The CG students were trained according to the traditional methodology of teaching basketball. The experimental group was divided into two subgroups - EG1 (n=69) and EG2 (n=58), which included students with initial and high levels of technical preparedness in basketball. It was found that after the pedagogical experiment, ball speed was increased by $24.6 \%$ and $4.6 \%$ in the experimental groups, in comparison
\end{abstract}

with 3.9\% in the control group. The results of the complex test, which characterizes the level of coordination, were improved by $24.7 \%$ and $13.8 \%$ in the experimental groups, and by $11.4 \%$ in the CG. This indicated the efficiency of the proposed methodology for using exercise machines to develop speed and coordination of students playing basketball.

Keywords Basketball, Exercise Machines, Physical Qualities, Students

\section{Introduction}

The generalization of the conclusions of the works of many scientists and the experience of practical work made it possible to state that technical preparedness is of great importance in sports games, and the ability to perform these actions quickly and accurately is the main condition for successful basketball players. According to many scientists [1, 2, 3, 4, 5], the performance of basketball 
movements requires certain physical qualities and properties of the musculoskeletal system. That is why basketball training helps to increase not only technical preparedness but also physical fitness of those involved. To date, there are a number of scientific works $[6,7,8,9$, 10] regarding the development and introduction of exercise machines in the educational and training process in sports games. However, the issue of using exercise machines in the educational and training process of student-athletes in basketball classes in modern pedagogical theory is studied insufficiently.

The quality of the educational and training process in basketball depends on its proper planning (the formation of content, tools, and methods of teaching technique and the development of physical qualities, the selection of physical activity parameters and their rational regulation), as well as on the objective assessment of the motor skills of young people who play basketball [11, 12, 13]. Almost all motor potential of a person is shown in games. Basketball differs in a wide range of techniques and the ways to use them. The natural movements, accessibility, wide range of actions and dosage, and the regulation of physical activity parameters ground a high variability of the means and methods of physical qualities development and increase the functional abilities of those who play basketball $[14,15,16]$. Along with the traditional approaches to the physical training of young people by means of basketball, associated mainly with the exercises with the ball and their combinations or in the game, it is possible to use additional means, including exercise machines and other equipment $[6,8,17]$.

The exercise machines are an additional tool that enhances the effectiveness of exercises. The expediency of using exercise machines during sports games training is based on the ability to perform movements according to the specified parameters and structure under conditions of strict dosage of physical activity, which makes it possible for people of different genders, ages, and physical fitness levels to apply them $[7,9,10]$. At the present stage of sports science, some experience has been gained in applying exercise machines for various sports games. However, the pedagogical aspect, which includes the development and use of the methods for the effective application of exercise machines in the educational process of students with different levels of technical preparedness involved in basketball remains poorly studied.

\subsection{The Aim}

The aim of the study is to develop and test the efficiency of the methodology for using exercise machines to develop speed and coordination of students with different levels of technical preparedness in the process of classes in basketball.

\section{Materials and Methods}

Research methods included:

- theoretical methods: the analysis and generalization of scientific, educational, and methodical literature and the experience of best practice in order to study current trends and contradictions in the organization of the physical education of students, advanced forms, tools, and methods of organizing the physical education process at higher education institutions, experience in implementing basketball in the students' physical education of various forms and the use of exercise equipment in various sports games;

- empirical methods: testing morpho-functional state of students who play basketball: body weight, height, vital lung capacity (VLC) and handgrip test; testing physical fitness of basketball players: $20 \mathrm{~m}$ run, 4x9 $\mathrm{m}$ shuttle run; testing the technical competence of basketball players: driving the ball, a comprehensive test (driving the ball from the middle line of the basketball court (right or left flank) with a double step and throws from under the basket for 1 min (the number of successful attempts, characterized by scoring the basket provided the technically correct execution of the exercise, was determined)); pedagogical experiment lasting 2 years (2019-2020) included the introduction of the methods of using exercise machines to develop speed and movements coordination in the process of playing basketball into the educational and training processes of students who play basketball. The pedagogical experiment involved 169 male students of different specialties of National Pedagogical Dragomanov University and Pereiaslav-Khmelnytskyi State Pedagogical University named after Hryhorii Skovoroda between the ages of 17 and 23. Experimental (EG) and control (CG) groups, which included 127 and 42 students respectively, were formed. The EG students played basketball in classes using exercise machines according to the methodology developed. The CG students were training according to the traditional methodology of teaching basketball. The experimental group was divided into two subgroups - EG1 (n=69) and EG2 (n=58), which included students with initial and high levels of technical preparedness in basketball;

- the method of statistical data processing was used for processing experimental data, qualitative and quantitative analysis of research results, checking their reliability. During the research, the authenticity of the difference between the indicators of the EG and CG students by means of the Student's criterion was determined. The significance for all statistical tests was set at $p \leq 0.05$. All statistical data were performed with the SPSS software, version 21, adapted to medical and biological research. 
The research was carried out according to the requirements of the Code of Ethics of National Pedagogical Dragomanov University, which was approved by the Academic Council of National Pedagogical Dragomanov University (protocol No. 8 of 27 August 2019) and implemented by the order of the Rector of the University (order No. 425 of 02 September 2019). According to its provisions, the members of the scientific process are guided by the principles of self-sufficiency, independence in the dissemination of knowledge and information, upholding honesty, fairness, responsibility, following ethical principles and rules of creative activity in order to establish confidence in the results of scientific achievements. Informed consent was received from all individuals who took part in this research and who could refuse participation at any time.

\section{Results}

In the course of our research, the necessary information about the level of morpho-functional state of young students of different levels of technical preparedness in basketball was obtained. It was found that the studied indicators of the students with a high level of technical preparedness in basketball (EG1) were significantly $(\mathrm{p} \leq 0.05-0.001)$ higher than those of the students with a low level of technical preparedness in basketball (EG2). Thus, the height of the EG1 male students was higher by $15.1 \mathrm{~cm}$ and body weight - by $10.3 \mathrm{~kg}$. The EG1 students' VLC indicators were higher than those of the EG2 students by $628.9 \mathrm{ml}$ and handgrip test indicators - by 8.6 kg.

It was also found that the physical qualities of students depend on the level of mastery of basketball techniques. Thus, the results of the $4 \times 9 \mathrm{~m}$ shuttle run of the EG1 students were significantly better than the ones of the EG2 students $(p \leq 0.05)$ by $0.3 \mathrm{~s}$; the results of the $20 \mathrm{~m}$ run of the EG1 students were also better than those of the CG students by $0.1 \mathrm{~s}$, but the difference was insignificant ( $\mathrm{p} \geq 0.05$ ) (Table 1).

Table 1. The physical fitness characteristics of the students with different levels of technical preparedness in basketball

\begin{tabular}{|c|c|c|c|}
\hline Tests & EG1 & EG2 & $\begin{array}{c}\text { Significance } \\
\text { value }\end{array}$ \\
\hline $\begin{array}{c}4 \times 9 \text { m shuttle } \\
\text { run, s }\end{array}$ & $9.2 \pm 0.07$ & $9.5 \pm 0.09$ & $\mathrm{p} \leq 0.05$ \\
\hline $20 \mathrm{~m}$ run, s & $3.8 \pm 0.04$ & $3.9 \pm 0.06$ & $\mathrm{p} \geq 0.05$ \\
\hline
\end{tabular}

Taking into account the results of our own research and the findings of many scientists, we have developed two exercise machines to improve the speed and coordination of students in basketball classes and substantiate the original methodology for their use in the training process. Therefore, we have developed a special exercise machine Dribblestand to train and improve ball handling techniques, increase the speed of technical actions, and coordinate movements in basketball (Fig. 1).

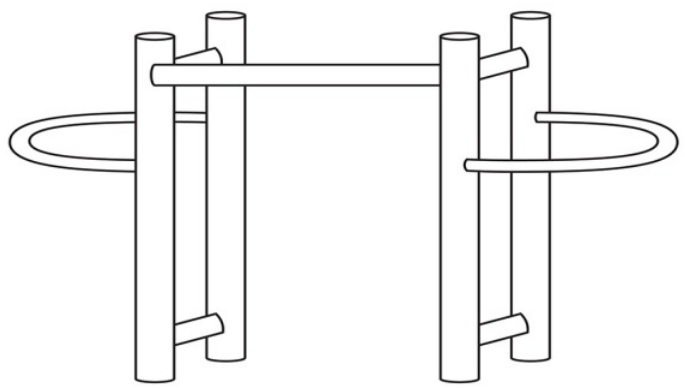

Figure 1. An exercise machine Dribblestand increasing speed and coordination of students playing basketball

This exercise machine is a plastic stand $180 \mathrm{~cm}$ wide with three crossbars, located at a height of $50 \mathrm{~cm}$ from the floor at an angle of $90-120^{\circ}$ and it is designed to train passing the ball from hand to hand hitting the floor. Driving the ball in basketball (dribbling) is considered to be the second main way to move the ball on the court after the pass; therefore, a high mastery of this technique is a basic principle of ball control in the game.

The machine is a simplified imitation of the defender's hands and is used to study the technique of driving the ball in controlled conditions by forming the muscular sense of the ball. The machine allows practicing different driving options - with the ball bouncing high from the surface of the court and the angle of the player's knees bending at $135-160^{\circ}$, with the ball bouncing low while the player is hiding it and bending knees at $90-120^{\circ}$ and combined dribbling. The variability of ball driving is provided by the improvement of hand coordination, which is manifested in the ability to pass the ball from hand to hand quickly, body balance, the frequency of hand movements (pace). And when performing the exercise on the machine, the leg muscles are strengthened because the exercise is performed in a semi-squat. The design solution provides the ability to adjust the height of the crossbars, which makes it possible to practice driving the ball by expanding the variability of manipulations with the ball at different heights. The exercise machine is aimed at the development of spatial and muscular sensitivity of movements, the ability to manipulate the ball, coordination, and frequency of movements.

Dribblestand is used on the following principle: a basketball player takes up a balanced stance with legs bent at an angle of $50-60^{\circ}$ and passes the ball sharply from hand to hand hitting the floor so that the ball passes under the bar. Three crossbars give the chance to work out techniques in different directions at the same time, changing them randomly or by a signal of the teacher or coach. Exercises on the machine can be performed concerning different tasks: time trial or the number of successful attempts.

To develop speed and coordination of students playing basketball, the exercise machine Coordination ladder was 
developed (Fig. 2).

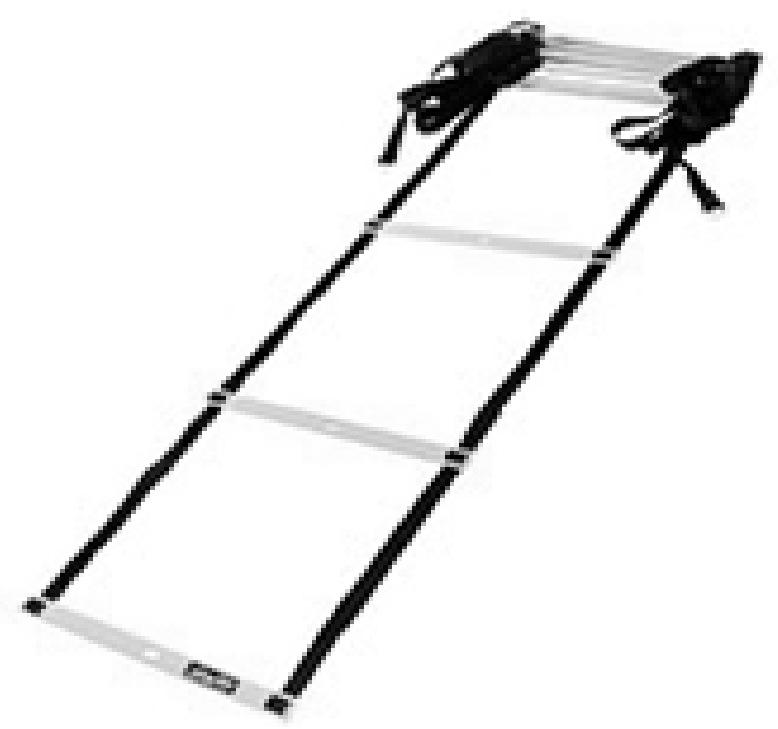

Figure 2. An exercise machine Coordination ladder to develop speed and coordination of students playing basketball

The presented machine is fixed at the top and bottom by a rope ladder with a total length of $6 \mathrm{~m}$ with 12 steps 4 $\mathrm{mm}$ thick, $36 \mathrm{~mm}$ wide, $500 \mathrm{~mm}$ long. The general technique of using this machine includes both homogeneous and different movements with changes in speed, pace, and direction. The use of the machine is based on the principle of complicating the conditions of movements with an emphasis on the development of speed and coordination of movements: the simultaneous performance of movements with different limbs on unstable support. Also, students with a high level of technical preparedness can perform movements with the ball simultaneously.

The specialties of physical activity planning in terms of applying the specified exercise machines take into account the rules of movement control, methodological provisions for the development of physical qualities, and the principles of the training equipment application in the training process. A characteristic feature of the process of physical training of students in the process of playing basketball with the use of exercise machines is the complex nature of the physical activity, which involves the simultaneous development of various abilities based on specific motor actions - guiding and special training exercises and game techniques. Physical activity planning in the process of developing the physical qualities of basketball players using training equipment is based on the initial level of physical fitness of students, the impact of exercises and training equipment on the body, the type of physical quality and nature of motor tasks, the patterns of adaptation and growth.

To develop the speed of students in the process of playing basketball, the exercise machine Dribblestand, providing exercises with an intensity level above the middle, was used. Developing speed, it was taken into account that the technique of performing the exercises should be relatively simple to ensure maximum speed, the execution time should be optimally long to make it possible to reduce speed, the rest interval between exercises should be as long as possible to ensure a full recovery. The physical activity was dosed individually according to the heart rate so that the recovery of the pulse to the initial $(90 \pm 10 \mathrm{bpm})$ after a standard exercise determined the duration of the rest break. Performing tasks with the ball, it was taken into consideration that the speed of driving the ball depends primarily on the height and angle of the ball bouncing: the higher the ball bouncing and the smaller its angle are within rational limits, the higher the speed is, and when the ball bouncing is low and close to vertical, the driving speed decreases. In classes with the students of an initial level of preparedness, the tasks on the exercise machines with an emphasis on the height and angle of the ball bouncing were used and with basketball players of a high level of technical preparedness, the tasks were performed at a variable pace, with a change of direction, with turns, passing the ball from hand to hand, from different starting positions, with limited visual control, etc.

The motor tasks for the development of ball speed implied 2-4 sets in a series; the set was given up to $30 \mathrm{~s}$, during which the speed was the maximum possible, and the rest between sets $-5 \mathrm{~s}$. The duration of rest between series was planned to restore the pulse to $90-100 \mathrm{bpm}$ (approximately 60-120 s), the number of series depended on the level of physical fitness of students - from 2 to 4 .

The speed development exercises on machines involved the use of the contrast method as the most effective one for the development of movement speed focusing on the technique in order to prevent disruption of the biomechanical structure of movements. To avoid a decrease in efficiency, motor tasks with maximum intensity were performed in the series. Thus, 2-4 sets were planned in a series; the motor task (a set) was given 5-6 s, during which the speed was the maximum possible, and the rest between sets $-5 \mathrm{~s}$. The duration of rest between series was planned to restore the pulse to $90-100 \mathrm{bpm}$ (approximately 60-120 s), the number of series depended on the level of physical fitness of students - from 4 to 6 . The speed development exercises were performed at the beginning of the main part of the class.

To develop coordination of movements while developing speed, the Coordination ladder machine was used. The methodology for coordination training involved the use of various exercises with a gradual increase in their coordination complexity using the series-repeated method of standard and variable exercises. The exercises on the Coordination ladder included both climbing in homogeneous and different ways, while the machine was hung up at different angles and vertically. The complexity of the exercises was gradually increased by applying 
additional ball control, limiting the action of the visual analyzer. In addition to the coordination of movements, moving up the ladder actively develops the strength of the working muscles. These exercises were performed at the beginning of the main part of the class simultaneously with speed development exercises in the series of 2-4 sets, 6-8 repetitions each. The rest between sets was extreme around 2-5 minutes (until heart rate would become $100 \pm 10 \mathrm{bpm}$ ), rest between series was complete (until the pulse would return to the initial state). In addition, it is advisable to regularly change the conditions of the exercises, the starting position, create additional difficulties, and increase their coordination complexity to improve the sense of the ball.

The use of physical activity for the development of one motor quality has an impact on improving other ones. The nature and magnitude of the developmental effect depend on the amount, nature, and method of planning physical activity and the initial level of physical fitness and technical preparedness of students. In terms of the basketball players with a low level of technical preparedness, the use of speed development exercises promotes the simultaneous development of aerobic capacity and power performance.

The features of the methodology for applying exercise machines in basketball classes are embedded in their design capabilities. For example, the Dribblestand and Coordination ladder machines are designed for individual or sequential ways of organizing classes. Depending on the work plan, the number of basketball players, and the level of their technical preparedness, a teacher or coach chooses the method of organizing classes. Sequential or circular methods are the most effective. Also, in order to develop physical qualities, applying developed exercise machines in basketball classes, the methods of combined exercise (game and competitive) were actively used, in addition to the method of interval exercise.

The use of exercise machines is possible at each stage of long-term basketball training. They are especially effective at the stage of initial training when the techniques and actions have significant deviations from the standard. The developed exercise machines make it possible to find mistakes in the technique of movement performance. The most common mistakes that beginner students make while learning basketball are making additional actions; deviation of movements in the direction or amplitude; violation of the general rhythm of action; increased muscle tension or an imbalance between tension and muscle relaxation. The main causes of mistakes in performing techniques are insufficient development of the necessary motor skills, fatigue, insufficient self-control, unfavorable external conditions, insufficient understanding of the motor task. The use of exercise machines helps to eliminate these mistakes, increasing the efficiency of the training process.

To test the efficiency of the original methodology for the development of physical qualities of students in basketball classes using the developed machines, a pedagogical experiment, in which students, who play basketball, with different levels of technical preparedness participated, was conducted.

The analysis of the results in physical fitness tests showed an improvement in the level of physical qualities development of the students of all the groups studied, but only the growth of speed and coordination of the EG1 students by $4.4 \%$ were significant $(\mathrm{p} \leq 0.05)$ (Table 2$)$. The growth of all other test results of the EG2 and CG students were not statistically significant ( $p>0.05)$.

An important indicator of the original methodology's efficiency is an increase in the level of technical preparedness of students (Table 3).

Table 2. The speed and coordination development dynamics of the EG1, EG2, and CG students who play basketball in the process of the pedagogical experiment (Mean \pm SD)

\begin{tabular}{|c|c|c|c|c|c|}
\hline Tests & Groups & Before the experiment & After the experiment & Growth, \% & Significance value \\
\hline \multirow{3}{*}{20 m run, s } & EG1 & $3.91 \pm 0.22$ & $3.74 \pm 0.24$ & $4.4 \%$ & $\mathrm{p} \leq 0.05$ \\
\cline { 2 - 6 } & EG2 & $3.76 \pm 0.20$ & $3.68 \pm 0.18$ & $1.6 \%$ & $\mathrm{p}>0.05$ \\
\cline { 2 - 6 } & CG & $3.89 \pm 0.24$ & $3.82 \pm 0.25$ & $1.8 \%$ & $\mathrm{p}>0.05$ \\
\hline \multirow{3}{*}{$4 \times 9$ m shuttle run, s } & EG1 & $9.51 \pm 0.61$ & $9.17 \pm 0.40$ & $3.6 \%$ & $\mathrm{p} \leq 0.05$ \\
\cline { 2 - 6 } & EG2 & $9.06 \pm 0.39$ & $8.79 \pm 9.07$ & $1.7 \%$ & $\mathrm{p}>0.05$ \\
\cline { 2 - 6 } & CG & $9.49 \pm 0.59$ & $9.35 \pm 0.55$ & $1.5 \%$ & $\mathrm{p}>0.05$ \\
\hline
\end{tabular}


Table 3. The technical preparedness dynamics of the EG1, EG2, and CG students who play basketball in the process of the pedagogical experiment (Mean \pm SD)

\begin{tabular}{|c|c|c|c|c|c|}
\hline Tests & Groups & Before the experiment & After the experiment & Growth, \% & Significance value \\
\hline \multirow{4}{*}{\begin{tabular}{c} 
Driving the ball, reps \\
\cline { 2 - 6 }
\end{tabular}} & EG1 & $27.6 \pm 4.0$ & $29.7 \pm 3.9$ & $7.3 \%$ & $\mathrm{p} \leq 0.05$ \\
\cline { 2 - 6 } & EG2 & $33.0 \pm 2.4$ & $34.2 \pm 1.9$ & $3.7 \%$ & $\mathrm{p} \leq 0.05$ \\
\hline \multirow{4}{*}{$\begin{array}{c}\text { Complex test, scored } \\
\text { points }\end{array}$} & EG1 & $27.7 \pm 3.9$ & $28.8 \pm 3.8$ & $3.9 \%$ & $\mathrm{p} \leq 0.05$ \\
\cline { 2 - 6 } & EG2 & $4.0 \pm 1.0$ & $4.9 \pm 0.9$ & $20.2 \%$ & $\mathrm{p} \leq 0.05$ \\
\cline { 2 - 6 } & CG & $5.4 \pm 0.6$ & $5.9 \pm 0.6$ & $15.9 \%$ & $\mathrm{p} \leq 0.05$ \\
\hline
\end{tabular}

Thus, a significant positive dynamics of mastering basketball technique of the students of all the groups studied was identified $(\mathrm{p} \leq 0.05)$. However, the growth of technical indicators of the EG1 students was higher than that of other basketball players. In particular, the frequency of driving the ball in the EG1 increased by $7.3 \%$, the results of the complex test improved by $20.2 \%$, while in the EG2, the increase in technical preparedness in terms of these tests was $3.7 \%$ and $15.9 \%$ respectively, and in the $\mathrm{CG}$, the test results increased by $3.9 \%$ and $7.1 \%$ respectively.

\section{Discussion}

To date, there are many exercise machines used in training and improving the technical skills of basketball players. Thus, the work of V. N. Pritykin and A. A. Geraskin [18] provided information about the tested technical devices for training shots in basketball: "Defender's Glove" complicates the conditions of throwing the ball, "Insert-ring" is used for balls bouncing with a low trajectory. The American developers of technical means of training shots in basketball offer devices that affect the parameters of the trajectory of the ball, modulate points in the plane of the basket in the form of various aiming objects and improve the accuracy (efficiency) of basketball shots without the ball bouncing from the backboard. Thus, the main technical means developed by the US specialists are orienting points on the backboard, spatial orienting points, additional equipment, special backboard, racks, and balls constructions, computer games-simulators [4, 10, 19].

To teach defense techniques in basketball, there are defensive exercise machines with a forced rhythm of presenting stimuli, and a leader of motor tasks with a free rhythm [17]. The exercise machines, tested by P. I. Donchenko [6] on the example of kicking the ball, make it possible to work in a progressive speed mode at different distances and purposefully affect both the speed of sensorimotor response and the accuracy of the spatial force parameters of action. The simulators presented in the study of Zh. L. Kozina, A. N. Vitsko, V. A.Vorobyova, I. V. Yarenchuk [7] are designed to increase the efficiency of jumping shots and ball rebound.

A. A. Mironov, E. A. Dukhovskoy, E. E. Yaskevich [20] describe successfully tested exercise machines developing special sensorimotor abilities in basketball - "Float" and "Grasp" developing hand muscle strength and "Shot" developing the vestibular apparatus, visual estimation and accuracy of muscular effort. G. P. Konstantinov [21] presented and tested an exercise machine for defensive actions training in basketball, which works by expanding the variability of manipulations with the ball in the air by installing and fixing the ball at different heights and the device designed for training rebound, tackling, putback in different ways and from different positions, the technique of guarding a player. K. M. Charikova work [17] describes the "Vibrado" machine for improving shots, which has the form of a sleeve with sensors and explains the biomechanical parameters of this technique with the help of innovative technologies: makes it possible to calculate the trajectory of the ball and correct it according to the required.

Given the high variability of motor actions in basketball and the relationship between the success of learning the game's technique with the development of motor skills of those involved, and despite the sufficient development of technical support for basketball training, the relevance of developing new affordable and effective exercise machines, developing physical qualities in the process of playing basketball at higher education institution is beyond doubt. The development of new types of exercise machines and the improvement of existing constructions create conditions for the skills growth of students who play basketball. At the same time, in the training process, it is necessary to give preference to the development and implementation of such exercise machines that stimulate high efficiency of the development of important motor skills, as well as muscle groups which are the most important in terms of coordination in basketball.

According to the existing scientific literature, the possibility of determining the conformity of quantitative or qualitative reproduction of motor actions with the use of exercise machines to the desired result (body state or accuracy of movements in space and time, degree of muscular effort, etc.) is fundamentally important in the 
process of training equipment development. The action of the specified exercise machine involves a local impact on the development of motor skills, the manifestation of which determines the success of mastering the skills of playing basketball. The use of these exercise machines based on the introduction of the original methodology into the educational and training process of students who play basketball ensures the work of muscles involved in performing basketball techniques and game actions without the ball, promotes the effective development of speed and coordination skills of students, and in general, improves the level of their sportsmanship in basketball.

The introduction of the machines developed and the methodology for their application in the educational and training processes of students playing basketball of the leading student teams of Ukraine has proved their high efficiency. Thus, in 2019, the women's basketball team of the National Pedagogical Dragomanov University "Dynamo-NPU" won the final series of the Women's Super League of Ukraine, becoming the champion for the third time in a row due to the use of Dribblestand and Coordination ladder during the training process. In 2019, the women's student basketball team became a silver medalist and in 2020, the winner of the Kyiv championship among students due to a significant increase in the development level of speed and coordination of female students as a result of training on machines developed. Besides, 3 female students of the university are members of the KSLI-Dynamo-NPU" team, which has repeatedly won the championship of Ukraine in basketball in the major leagues. The men's national basketball team of the university systematically includes Dribblestand and Coordination ladder in the process of physical training, thanks to which it has repeatedly won the championship of Kyiv among students in 2018-2020.

The results of our research complement the findings of many scientists [22-38] and expand them.

\section{Conclusions}

1. Basketball includes a wide range of natural movements and actions with the ball, which makes it possible to use them in the motor training of students. The exercise machines are an additional tool that enhances the effectiveness of physical exercises. The expediency of using exercise machines during the sports games training is based on the ability to perform movements according to the specified parameters and structure under conditions of strict dosing of physical activity, which determines their availability.

2. To increase the efficiency of the students' physical training, two exercise machines Dribblestand and Coordination ladder were designed to increase the speed and coordination of students playing basketball. The principle of the exercise machines is controlled muscular activity, which provides psychophysical readiness to effectively perform the basketball techniques and game actions without the ball. The exercise machines have a combined effect, which makes it possible to influence the development of special motor skills and train basketball techniques simultaneously by improving the structure of movements and muscle sense. Developing exercise machines, the need for the simplicity of design and application technology, and maximum accessibility for students who play basketball with different levels of technical preparedness were taken into account.

3. The original methodology for applying exercise machines in order to develop the physical qualities of students in basketball classes is developed. The complex nature of physical activity involved the simultaneous development of various abilities is based on the implementation of the following means: guiding and special training exercises and game techniques. Physical activity planning is based on taking into account the initial level of students' physical fitness, the direction of the impact of exercises and training devices on the body, the type of physical quality and nature of motor tasks, the patterns of adaptation and growth. The methodology for using the designed exercise machines in order to develop physical qualities of students in basketball classes includes the use of the methods of interval exercises (series-repeated method) and combined exercises (circular, game, and competitive methods) to influence the development of speed and coordination. In the process of increasing the developmental effect, the amount and intensity of physical activity were increased, rest time was reduced, the nature of rest was changed from passive to active, the coordination complexity of exercises was increased, and the conditions of performing exercises were complicated.

4. The efficiency of the original methodology for applying the designed exercise machines in order to develop the physical qualities of students in the process of playing basketball from the standpoint of improving the indicators of physical fitness and technical preparedness was proved. The improvement of the level of physical qualities development of students of all the groups studied was established, however, the growth of the speed and coordination indicators of the EG1 basketball players by $4.4 \%$ was proved to be significant $(\mathrm{p} \leq 0.05)$. The positive reliable dynamics of the level of mastering basketball technique of the students of all the groups studied were identified and the growth of most indicators of the EG1 students' technical preparedness was higher $(\mathrm{p} \leq 0.05)$ that of other 
basketball players. In particular, the frequency of driving the ball in the EG1 increased by $7.3 \%$, the results of the complex test improved by $20.2 \%$, while in the EG2, the increase in technical preparedness in terms of these tests was $3.7 \%$ and $15.9 \%$ respectively, and in the CG, the test results increased by $3.9 \%$ and $7.1 \%$ respectively. Thus, the developmental effect of basketball classes with the use of technical equipment, which is the direct task of the methodology developed, confirmed the reliable dynamics of the development of physical qualities and technical preparedness of the students of experimental groups.

\section{Disclosure Statement}

No author has any financial interest or received any financial benefit from this research.

\section{Conflict of Interest}

The authors state no conflict of interest.

\section{REFERENCES}

[1] O. Candra. "The effect of concentration training on shooting free throw in basketball game", International Journal of Human Movement and Sports Sciences, Vol.8, No. 6A, pp. 29-35, 2020. doi: 10.13189/saj.2020.080705.

[2] C. Castagna, G. Abt, V. Manzi, G. Annino, E. Padua, S. Dottavio, "Effect of recovery mode on repeated sprint ability in young basketball players", The Journal of Strength and Conditioning Research, Vol.22, No.3, pp. 923-929, 2008. doi: 10.1519/JSC.0b013e31816a4281.

[3] K. Marić, R. Katić, M. Jelicić, "Relations between basic and specific motor abilities and player quality of young basketball players". Collegium Antropologicum, Vol.37, No.Suppl 2, pp. 55-60, 2013.

[4] E. J. Santos, M. A. Janeira. "The effects of resistance training on explosive strength indicators in adolescent basketball players". Journal of Strength and Conditioning Research, Vol.26, No.10, pp. 2641-2647, 2012. https://doi.org/10.1519/JSC.0b013e31823f8dd4.

[5] C. Savu, C. Pehoiu. "Particularities of the education of the coordination and acquisition of the curriculum of physical education by using the specific means of playing basketball". Revista Romaneasca Pentru Educatie Multidimensionala, Vol.10, No.4, pp. 217-227, 2018. https://doi.org/10.18662/r $\mathrm{rem} / 83$.

[6] P. I. Donchenko. "Training technical means of training and control in basketball", Tashkent: Medicine, 1984.

[7] Zh. L. Kozina, A. N. Vitsko, V. A.Vorobyova, I. V. Yarenchuk. "Basketball as a factor of harmonious combination of mental and physical development of students", Pedagogy, Psychology and Medical and Biological Problems of Physical Education and Sports, Vol.6, pp. 113-117, 2008.

[8] G. Griban, K. Prontenko, Yu. Kostyuk, P. Tkachenko, T. Yavorska, Ye. Zhukovskyi, V. Shaverskiy. "Formation of middle school pupil movements using basketball", Journal of Physical Education and Sport, Vol.18, No.1, pp. 304-309, 2018. doi: 10.7752/jpes.2018.01041.

[9] J. Calleja-González, N. Terrados, J. Mielgo-Ayuso, A. Delextrat, I. Jukic, A. Vaquera, L. Torres, X. Schelling, M. Stojanovic, S. M. Ostojic. "Evidence-based post-exercise recovery strategies in basketball", The Physician and Sports Medicine, Vol.44, No.1, pp. 74-78, 2016. https://doi.org/10.1080/00913847.2016.1102033.

[10] H. C. Crockett, J. M. Wright, M. W. Madsen, J. E. Bates, H. G. Potter, R. F. Warren. "Sacral stress fracture in an elite college basketball player after the use of a jumping machine". The American Journal of Sports Medicine, Vol.27, No.4, pp. 526-528, 1999. https://doi.org/10.1177/0363546599027004 2001.

[11] M. Elgammal, I. Hassan, N. Eltanahi, H. Ibrahim. "The effects of repeated sprint training with blood flow restriction on strength, anaerobic and aerobic performance in basketball", International Journal of Human Movement and Sports Sciences, Vol.8, No.6, pp. 462-468, 2020. doi: 10.13189/saj.2020.080619.

[12] J. Padulo, G. Attene, G. M. Migliaccio, F. Cuzzolin, S. Vando, L. P. Ardigo, "Metabolic optimisation of the basketball free throw", Journal of Sports Sciences, Vol.33, No.14, pp. 1454-1458, 2015. doi: 10.1080/02640414.2014. 990494.

[13] G. Boccolini, A. Brazzit, L. Bonfanti, G. Alberti. "Using balance training to improve the performance of youth basketball players", Sport Sciences for Health, Vol.9, No.2, pp. 3742, 2013. https://doi.org/10.1007/s11332-013-0143-z.

[14] A. Domeika, A. Slapšinskaite, S. Razon, L. Šiupšinskas, I. Kliziene, M. Dubosienè, "Effects of an 8-week basketball-specific proprioceptive training with a single-plane instability balance platform". Technology and Health Care: Official Journal of the European Society for Engineering and Medicine, Vol.28, No.5, pp. 561-571, 2020. https://doi.org/10.3233/THC-208002.

[15] M. Z. Milovanović, N. R. Pažin, V. D. Mrdaković, F. F. Erčulj, S. T. Jakovljević. "Shooting accuracy in children's basketball: Do equipment dimensions influence static and dynamic performances?", Journal of Sports Sciences, Vol.38, No.23, pp. 2740-2749, 2020. https://doi.org/10.1080/02640 414.2020.1798716.

[16] J. Fernandez-Rio, N. Terrados, B. Fernandez-Garcia, O. E. Suman. "Effects of vibration training on force production in female basketball players", Journal of Strength and Conditioning Research, Vol.24, No.5, pp. 1373-1380, 2010. https://doi.org/10.1519/JSC.0b013e3181d1d2b1.

[17] K. M. Charikova. "Training complex for the development of the ability to differentiate the initial speed of the ball when performing a long pass in basketball". Slobozhansky Scientific and Sports Bulletin, Vol.4, No.31, pp. 55-59, 2012. 
[18] V. N. Pritykin, A. A. Geraskin. "Creation of technical means for basketball players' throwing training". Modern High Technologies, Vol.7, No.1, pp. 181-188, 2016.

[19] J. P. DiFiori, A. Güllich, J. S. Brenner, J. Côté, B. Hainline, E. Ryan, R. M. Malina. "The NBA and youth basketball: recommendations for promoting a healthy and positive experience", Sports Medicine, Vol.48, No.9, pp. 2053-2065, 2018. https://doi.org/10.1007/s40279-018-0950-0.

[20] A. A. Mironov, E. A. Dukhovskoy, E. E. Yaskevich. "New types of basketball simulators", Theory and Practice of Physical Education, Vol.8, pp.46-47, 2008.

[21] G. P. Konstantinov. "Portable trainer for improving the defensive actions of basketball players". Retrieved from https://findpatent.ru/patent/225/2259857.html.

[22] G. Ziv, R. Lidor. "Vertical jump in female and male basketball players - a review of observational and experimental studies", Journal of Science and Medicine in Sport, Vol.13, No.3, pp. 332-339, 2010. https://doi.org/10.1016/j.jsams.2009.02.009.

[23] B. Aryanto, P. Sukoco, R. Lumintuarso. "The validity of construct analysis on assessment instrument of basketball skill for senior high school in Yogyakarta City", International Journal of Human Movement and Sports Sciences, Vol.8, No.5, pp. 193-198, 2020. doi: 10.13189/saj.2020.080506.

[24] C. Savu, C. Pehoiu. "Developing force by means of basketball in the physical education lesson". Revista Romaneasca Pentru Educatie Multidimensionala, Vol.10, No.1, pp. 145-154, 2018. https://doi.org/10.18662/rrem/25.

[25] J. Sarvestan, M. Cheraghi, E. Shirzad, Z. Svoboda. "Experience related impacts on jump performance of elite and collegiate basketball players; investigation on force-time curvature variables", Sport Mont, Vol.17, No.2, pp. 23-28, 2019. doi: 10.26773/smj.190604.

[26] K. Prontenko, I. Bloshchynskyi, G. Griban, Ye. Zhukovskyi, T. Yavorska, P. Tkachenko, D. Dzenzeliuk, N. Dovgan, S. Bezpaliy, V. Andreychuk. "Formation of readiness of future physical culture teachers for professional activity", Universal Journal of Educational Research. Vol.7, No.9, pp. 1860-1868, 2019. doi: 10.13189/ujer.2019.070903.

[27] S. Prysiazhniuk, V. Tolubko, D. Oleniev, Yu. Parczevskyy, K. Prontenko, G. Griban, O. Zhyrnov. The influence of physical activities on biological age parameters of the first-year female students from the special medical department, Journal of Physical Education and Sport, Vol.18, No.2, 561-564, 2018. doi: 10.7752/jpes.2018.02081.

[28] K. Prontenko, G. Griban, A. Aloshyna, S. Bezpalyi, T. Yavorska, S. Hryshchuk, P. Tkachenko, D. Dzenzeliuk, I. Bloshchynskyi. "The physical development and functional state as the important components of the students' health", Wiadomości Lekarskie, Vol.72 No.12, part 1, pp. 2348-2353, 2019. doi: 10.36740/WLek201912115.

[29] K. Prontenko, G. Griban, I. Bloshchynskyi, I. Melnychuk, D. Popovych, V. Nazaruk, S. Yastremska, D. Dzenzeliuk, I. Novitska. "Improvement of students' morpho-functional development and health in the process of sport-oriented physical education", Wiadomości Lekarskie, Vol.73, No.1, pp. 161-168, 2020. doi: 10.36740/WLek202001131.

[30] G. Griban, T. Yavorska, P. Tkachenko, O. Kuvaldina, Z. Dikhtiarenko, E. Yeromenko, A. Lytvynenko, N. Hresa, I. Okhrimenko, I. Ovcharuk, K. Prontenko. "Motor activity as the basis of a healthy lifestyle of student youth", Wiadomości Lekarskie, Vol.73, No.6, pp. 1199-1206, 2020. doi: 10.36740/WLek202006123.

[31] O. Mozolev, I. Bloshchynskyi, O. Alieksieiev, L. Romanyshyna, L. Zdanevych, I. Melnychuk, K. Prontenko, V. Prontenko. "Influence of modern fitness technologies on the state of health and development of motor abilities of 17-19-year-old female students", Journal of Physical Education and Sport, Vol.19, (Supplement issue 3), pp. 917-924, 2019. doi: 10.7752/jpes.2019.s3132.

[32] G. Griban, O. Kobernyk, N. Terentieva, O. Shkola, Z. Dikhtiarenko, I. Mychka, E. Yeromenko, L. Savchenko, A. Lytvynenko, K. Prontenko. "Formation of health and fitness competencies of students in the process of physical education", Sport Mont, Vol.18, No.3, pp. 73-78, 2020. doi: 10.26773/smj.201008.

[33] O. Azhyppo, V. Pavlenko, V. Mulyk, K. Mulyk, L. Karpets, T. Grynova, M. Sannikova. "Direction of teaching the subject of physical education by taking into account opportunities of institution of higher education and interests of student youth", Journal of Physical Education and Sport, Vol.18, No.1, pp. 222-229, 2018. doi:10.7752/jpes.201 8.01029

[34] K. Prontenko, G. Griban, N. Dovgan, O. Loiko, V. Andreychuk, P. Tkachenko, D. Dzenzeliuk, I. Bloshchynskyi "Students' health and its interrelation with physical fitness level", Sport Mont, Vol. 17, No.3, pp. 41-46, 2019. doi: 10.26773/smj.191018.

[35] O. Mozolev, M. Khmara, I. Shorobura, I. Bloshchynskyi, K. Prontenko, O. Polishchuk, L. Zdanevych, K. Krutii. "Comparative analysis of the effectiveness of Polish and Ukrainian basic training programs in physical education for 9-10-year-old pupils", Universal Journal of Educational Research, Vol.7, No.11, pp. 2345-2351, 2019. doi: 10.13189/ujer.2019.071112.

[36] G. Griban, K. Prontenko, V. Zhamardiy, P. Tkachenko, M. Kruk, Yu. Kostyuk, Ye. Zhukovskyi. "Professional stages of a physical education teacher as determined using fitness technologies", Journal of Physical Education and Sport, Vol.18, No.2, pp. 565-569, 2018. doi: 10.7752/jpes.2018.02 082 .

[37] N. Kozhokar, Y. Kurnyshev, Y. Paliichuk, L. Balatska, O. Yarmak, Y. Galan. "Monitoring of the physical fitness of 17-19 year old young men during physical education". Journal of Physical Education and Sport, Vol.18, No.Suppl 4, pp. 1939-1944, 2018. doi: 10.7752/jpes.2018.s4286.

[38] G. Griban, O. Kuznietsova, P. Tkachenko, D. Oleniev, O. Khurtenko, Z. Dikhtiarenko, E. Yeromenko, A. Lytvynenko, A. Khatko , L. Pustoliakova, "Formation of the students' volitional qualities in the process of physical education", International Journal of Human Movement and Sports Sciences, Vol.8, No.6, pp. 505-517, 2020. doi: 10.13189/saj.2020.080625. 